\title{
PERANCANGAN LANSEKAP KAWASAN RUMAH SUSUN MAHASISWA UNIVERSITAS LAMPUNG SEBAGAI LABORATORIUM PRAKTIKUM PERTANIAN
}

\author{
Ika Fatmasari, Tri Dewi Andalasari \& Kushendarto \\ Jurusan Budidaya Pertanian, Fakultas Pertanian Universitas Lampung \\ Jl.Prof. Soemantri Brodjonegoro, No.1 Bandar Lampung 35145 \\ E-mail: fatmasari_ika@yahoo.com
}

\begin{abstract}
ABSTRAK
Laboratorium merupakan salah satu kebutuhan civitas akademi di Universitas, sehingga perencanaan pembangunan laboratorium harus cermat dan mempertimbangkan banyak hal. Dengan adanya laboratorium yang direncanakan oleh pihak Universitas Lampung dengan kementrian kelautan pada tahun 2010 yaitu penyediaan laboratorium praktikum dan perbaikan kualitas pendidikan, namun sampai saat ini usaha tersebut belum seluruhnya memenuhi harapan karena belum adanya kesesuaian antara keinginan akademika dengan laboratorium praktikum yang diusahakan. Penelitian ini bertujuan untuk membuat perancangan lansekap area sekitar (outdoor), serta penataan fasilitas pendukung (hardscape) dengan hasil akhir berupa gambar desain, sehingga tercipta perancangan lansekap kawasan Rusunawa Unila yang sesuai dengan laboratorium Praktikum Pertanian. Berdasarkan hasil analisis dan sintesis, kawasan Rusunawa Unila berpotensi dijadikan area laboratorium praktikum terpadu untuk Fakultas Pertanian dan dapat dikembangkan menjadi 7 zona, yaitu Zona penerimaan A, Zona penerimaan B, Zona olahraga, Zona ruang terbuka hijau, Zona praktikum, Zona parkiran umum, Zona Rusunawa Unila.
\end{abstract}

Kata Kunci: Laboratorium, Praktikum, Rusunawa, Zonasi.

\section{PENDAHULUAN}

Universitas Lampung (Unila) merupakan Perguruan Tinggi Negeri di Provinsi Lampung yang berdiri berdasarkan keputusan Menteri Perguruan Tinggi Ilmu Pendidikan (PTIP) Nomor 195 Tahun 1965, pada tanggal 23 September 1965, kemudian dikukuhkan menjadi Perguruan Tinggi Negeri dengan Keputusan Presiden Nomor 73 Tahun 1966, sehingga Universitas menjadi pilihan pertama bagi siswa yang berada di Provinsi Lampung dan sekitarnya untuk menuju ke jenjang pendidikan yang lebih tinggi.

Pada tahun 2005, Unila membangun fasilitas untuk mahasiswa baru yaitu Rumah Susun Mahasiswa (Rusunawa), yang selesai tahun 2006. Bangunan tersebut memiliki empat tingkat dengan 96 kamar, 24 kamar tersedia pada setiap tingkatnya. Kondisi bangunan Rusunawa bertingkat empat tersebut sudah mulai dihuni oleh mahasiswa/mahasiswi pada tahun 2010, dua tingkat bagian bawah untuk mahasiswa dan dua tingkat bagian keatas untuk mahasiswi. Hadirnya Rusunawa dapat membantu mahasiswa baru, khususnya mahasiswa yang berprestasi dapat mengenyam pendidikan serta tempat tinggal.

Rusunawa memiliki fungsi dengan baik jika didukung oleh faktor internal dan faktor eksternal. Faktor internal meliputi fasilitas yang terdapat di dalam
Rusunawa sedangkan faktor eksternal merupakan faktor pendukung yang berada di sekitar Rusunawa misalnya ruang terbuka hijau (RTH).

Kawasan lansekap Rusunawa Unila dirancang mencakup area rawa dan lahan praktikum mahasiswa unila, khususnya mahasiswa Fakultas Pertanian. Kawasan rawa dapat dimanfaatkan untuk praktikum Jurusan perikanan dan Jurusan Agroteknologi yang berfungsi sebagai tempat belajar mahasiswa baru. Namun, laboratorium praktikum bisa digunakan sebagai ruang terbuka hijau (RTH) kampus yang nyaman dan berfungsi sebagai tempat belajar di ruang terbuka (open space).

Laboratorium merupakan salah satu kebutuhan civitas akademi di Universitas, sehingga perencanaan pembangunan laboratorium harus cermat dan mempertimbangkan banyak hal. Lahan praktikum yang ada pada saat ini belum dilakukan penggabungan antara penataan elemen lunak (softscape) dan elemen keras (hardscape) untuk memperlancar kegiatan praktikum mahasiswa. Oleh sebab itu perancangan lahan praktikum akan menghadirkan sirkulasi jalan setapak (footpath), gazebo sebagai tempat interaksi antara praktikan dengan asisten osen/dosen, gudang pupuk dan alat-alat pertanian. 
Pertumbuhan dan perkembangan tanaman sangat dipengaruhi oleh faktor lingkungan: jenis tanah, $\mathrm{pH}$ tanah, topografi, kecepatan angin, curah hujan, dan kelembaban. Oleh karena itu pertimbangan dalam pemilihan tanaman menjadi lebih kompleks.

Suharto (1994), taman (landscape) adalah wajah dan karakter bahan atau tapak bagian muka bumi dengan segala kehidupan dan apa saja yang ada di dalamnya, baik yang bersifat alami maupun buatan manusia yang merupakan bagian atau total lingkungan hidup manusia beserta mahluk hidup lainnya, sejauh mata memandang, sejauh segenap indra kita dapat menangkap, dan sejauh imajinasi kita dapat membayangkan. Menurut( Arifin dan Arifin, 2000) dalam pengertian taman secara terbatas merupakan sebidang lahan yang ditata sedemikian rupa sehingga mempunyai keindahan, kenyamanan, dan keamanan bagi pemiliknya atau penggunanya.

Sinta dan Muharnanto (2004), taman merupakan sebuah areal yan mempunyai ruang dalam berbagai kondisi. Taman dapat mempengaruhi emosi manusia, dengan menikmati keindahannya yang berupa rasa nyaman, aman, penuh misteri dan rasa keingintahuan, serta romantis. Namun, kehadiran aneka taman yang indah dapat memberikan nilai tambah bagi suatu areal dan menjadikanya lebih berguna.

Arsitektur lansekap adalah ilmu dan seni perencanaan (planning) dan perancangan (design) serta pengaturan dari pada lahan, penyusunan elemenelemen alam dan buatan melalui aplikasi ilmu pengetahuan dan budaya, dengan memperhatikan keseimbangan kebutuhan pelayanan dan pemeliharaan sumber daya, hingga pada akhirnya dapat disajikan suatu lingkungan yang fungsional dan estetis (Hakim dan Utomo, 2008).

Suharto (1994), Arsitektur Pertanaman adalah ilmu yang mempelajari pengetahuan ruang dan masa guna didapatkan suatu lingkungan hidup yang harmonis yang secara fungsional berguna dan secara estetis indah, sehingga terpenuhi kebutuhan jasmani dan rohani mahluk di dalamnya.

Perancangan lansekap merupakan pemikiran kombinasi elemen soft material dan elemen hard material, serta menghasilkan produk teknis seni, tetapi penyajiannya harus selalu teknis dan semua yang digambarkan harus jelas dan bisa dilaksanakan (Hakim, 2003).

Simond (1983), mengemukakan bahwa perancangan lansekap merupakan suatu proses sintesis kreatif, kontinyu, tanpa akhir dan dapat bertambah. Di dalam perencanaan lansekap terdapat urutan kerja yang panjang yang terdiri dari bagian-bagian pekerjaan yang paling berhubungan, sehinga bila terjadi perubahan dari suatu bagian akan mempengaruhi bagian lain.

Irwan (2005) menyatakan bahwa, untuk memperdalam kajian arsitek lansekap dibutuhkan pemahaman tentang pengaturan ruang dan masa di alam terbuka juga memerlukan "ilham"sebagai wujud dari seni, sehingga dapat menghubungkan elemen-elemen lansekap alami dan buatan manusia.

\section{METODE PENELITIAN}

Penelitian dilaksanakan dalam dua tahap, yaitu tahap inventarisasi tapak dan tahap perancangan yang dilaksanakan dari Februari 2010 sampai Maret 2012. Secara administrasi lokasi penelitian adalah area rawa, area ruang luar, area dalam Rumah Susun Mahasiswa Universitas Lampung, dan perancangan lansekap sebagai laboratorium lapangan terpadu yang terletak di lingkungan Universitas Lampung Jl. Soematri Brojonegoro, Kelurahan Gedung Meneng, Kotamadya Bandar Lampung, Provinsi Lampung. Lokasi Rusunawa (Gambar 1), berbatasan dengan kolam renang Unila (sebelah Utara), terminal Rajabasa (sebelah Selatan), tanah warga/tanaman melinjo (sebelah Barat), dan rawa/ embung (sebelah Timur).

Bahan yang digunakan adalah tapak berupa(area sekitar Rusunawa) (Gambar 2), site existing (peta kontur dan vegetasi existing). Secara geografis, daerah studi terletak antara $105^{\circ} 14^{\prime} 51^{\prime \prime} \mathrm{BT}$ dan $105^{\circ} 15^{\prime} 34^{\prime \prime} \mathrm{BT}$, serta diantara $5^{\circ} 22^{\prime} 17^{\prime \prime}$ LS dan $5^{\circ} 23^{\prime} 17^{\prime \prime}$ LS (Badan Pusat Statistik, 2005). Daerah perancangan lansekap dekat dengan terminal Rajabasa sebagai gerbang Lampung dengan luas kurang lebih $33.412 \mathrm{~m}^{2}$. Area sekitar Rusunawa memiliki danau dengan luas \pm 9045 $\mathrm{m}^{2}$ dan bangunan rusunawa dengan luas $\pm 1438 \mathrm{~m}^{2}$.

Rancangan Rusunawa Unila menggunakan metode Gold dalam Hakim (1987) yang terdiri dari beberapa tahapan yang harus dicapai, yang meliputi kegiatan: inventarisasi, analisis, sintesis, konsep, dan desain, dengan hasil akhir berupa rancangan lansekap Rusunawa Unila. Gambaran tentang tahapan perencanaan tersebut dapat dilihat pada (Gambar 3).

Kondisi awal tapak topografi tapak secara keseluruhan memiliki kontur dengan kemiringan berkisar antara 4\% sampai dengan 10\%. Tingkat kemiringan yang sangat curam terdapat pada daerah pinggir rawa. Tingkat kemiringan ditandai dengan rapat atau renggangnya garis kontur. Semakin rapat garis kontur maka semakin curam dearah tersebut dan sebaliknya semakin renggang garis kontur maka semakin datar (Gambar 4). 


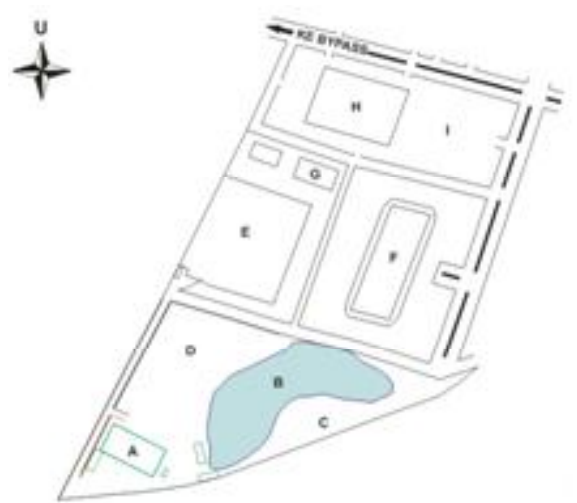

Gambar 1. Denah Rusunawa Unila. A. Rusunawa, B. Rawa Rusunawa, C. Tempat praktikum mahasiswa, D. Tanah kosong, E. Kolam renang Unila, F. Lapangan olahraga Unila, H. Gedung serba guna (GSG), I. Parkiran GSG.
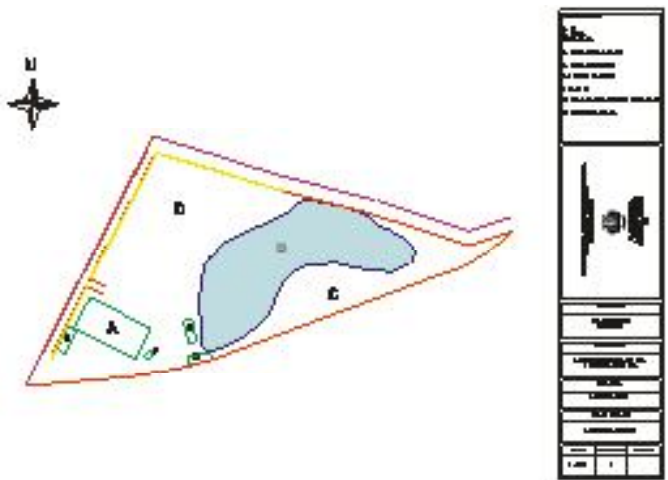

Gambar 2. Area sekitar Rusunawa. A. Rusunawa, B. Rawa Rusunawa, C. Lahan praktikum, D. Lahan kosong, E.Tempat parkir, F. Tempat jenset mesin, G. Bekas kandang perternakan, H. Rumah penjaga.

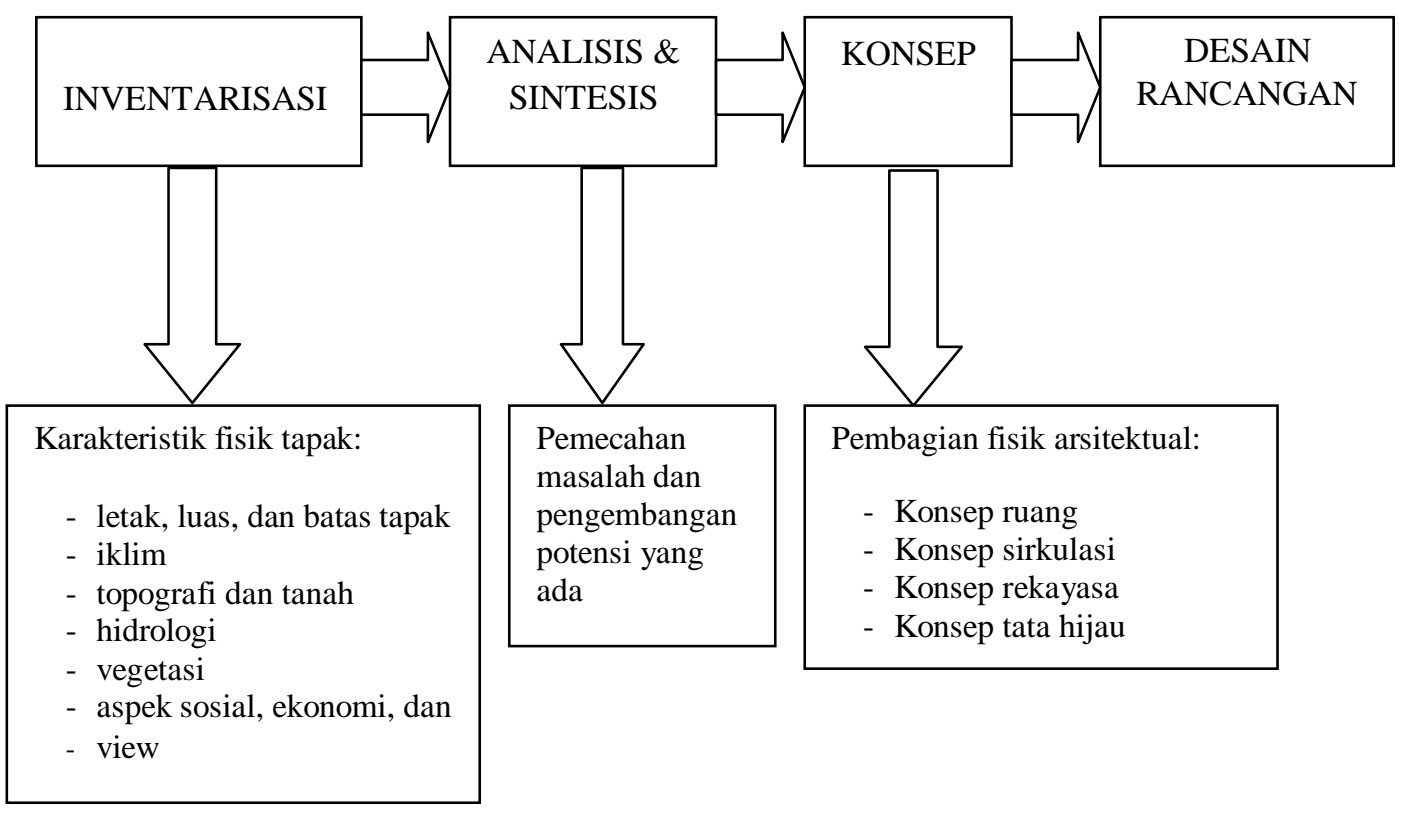

Gambar 3. Tahapan perancangan lansekap Rusunawa Universitas Lampung. 


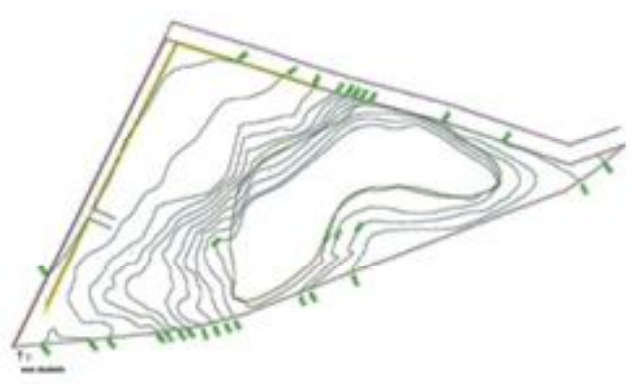

Gambar 4. Peta kontur kawasan Rusunawa Universitas Lampung.

Evaluasi sifat hujan wilayah kota Bandar Lampung dengan curah hujan $381 \mathrm{~mm}^{3}$ pada bulan Januari 2010, dan pada bulan Desember dengan curah hujan $311 \mathrm{~mm}^{3}$. suhu udara maksimum mencapai $32,5^{\circ} \mathrm{C}$ serta suhu minimum pada kisaran $21,5^{\circ} \mathrm{C}$ dengan suhu udara ratarata sebesar $26,8^{\circ} \mathrm{C}$ dengan kelembaban rata-rata harian sebesar $80 \%$.

Hidrologi pada kawasan tapak sumber air yang digunakan untuk kebutuhan berasal dari air tanah yang didapat dari sumur bor dan rawa yang terdapat pada kawasan.Vegetasi pada daerah penelitian yang didominasi oleh semak/pohon yang tumbuh alami, seperti alang-alang, pohon melinjo, pohon beringin dan pohon bambu.

\section{HASIL DAN PEMBAHASAN}

Data pengamatan yang diperoleh dari inventarisasi lapangan selanjutnya dilakukan analisis dan sintesis (Tabel 1). Analisis merupakan kegiatan yang dilakukan untuk mengetahui potensi dan kendala yang ada di kawasan Rusunawa Universitas Lampung, sedangkan sintesis adalah untuk pemanfaatan potensi yang ada pada tapak dengan baik dan mengendalikan kendala atau masalah-masalah yang ada pada hasil inventarisasi di kawasan Rusunawa tersebut.

Konsep ruang (zonasi) lansekap yang dikembangkan pada perancangan lansekap kawasan ini terbagi menjadi tujuh konsep (Gambar 5) ruang yang meliputi: Zona penerimaan A, Zona penerimaan B, Zona olah raga, Zona ruang terbuka hijau, Zona praktikum mahasiswa Fakultas Pertanian Unila, Zona parkiran umum, Zona Rusunawa.

Bagian zona secara spesifik untuk zona laboratorium praktikum pertanian sebagai berikut:Zona penerimaan (entrance zone) terletak pad pintu masuk utama Rusunawa yang berada di sebelah Utara dan di sebelah Timur (Gambar 6A). Zona yang memiliki luas $\pm 900 \mathrm{~m}^{2}$ dan luas $\pm 1200 \mathrm{~m}^{2}$ ini berfungsi sebagai area penyambut pengunjung mahasiswa dan dosen. Oleh karena itu didalam zona ini dibangun seperti gapura dengan taman yang dapat mencirikan suasana di Rusunawa.

Fasilitas yang dibutuhkan pada zona ini antara lain pintu gerbang dua arah (keluar dan masuk), pos keamanan Rusunawa, lampu penerangan, gapura.

Zona olahraga (Gambar 6B) adalah salah satu tempat beraktifitasnya badan yang digunakan untuk penghuni Rusunawa dan untuk umum. Zona yang memiliki luas $\pm 4835 \mathrm{~m}^{2}$ ini terletak di bagian sebelah Utara sebelah pintu penerimaan A, hal ini dimaksudkan agar lebih dekat masuk dari pinggir jalan tanpa dengan berbelok-belok. Fasilitas ini mahasiswa dapat menggunakannya dengan sebaik mungkin, sarana olahraga yang telah disediakan adalah lapangan softball/ baseball, lapangan futsal dan parkir motor.

Konsep tata hijau pada zona ruang terbuka hijau mengambil tema arboretum yang terdiri dari beberapa koleksi tanaman direncanakan pada zona ini antara lain akasia, pandan pandanan, glodokan tiang (Gambar 6C).

Konsep tata hijau pada zona praktikum merupakan taman koleksi yang terdiri dari beberapa tanaman koleksi buah-buahan dan sayuran sebagai bahan praktikum mahasiswa. Beberapa tanaman buah yang direncanakan pada zona praktikum ini antara lain durian, belimbing, jambu air, jambu biji, alpukat, dan sawo. Tanaman sayuran yang direncanakan antara lain sawi, kangkung, bayam, kacang panjang, mentimun, semangka, dan melon.

Pada area kolam pemancingan ditanami pandanpandanan dan pohon kurma (Gambar 7). Zona lahan praktikum memiliki luas $\pm 11988 \mathrm{~m}^{2}$, zona ini digunakan sebagai lahan praktikum mahasiswa pertanian baik dari budidaya pertanian maupun perikanan. Petak-petak kolam itu setengahnya digunakan untuk pemijahan ikan dan sebagai tempat praktikum mahasiswa jurusan Budidaya Perikanan.

Zona parkir umum memiliki luas $\pm 3566 \mathrm{~m}^{2}$, area ini menyediakan lahan parkir yang cukup luas menampung banyak mobil. Sistem yang digunakan yaitu sistem keluar masuk dengan pintu yang berbeda dengan tujuan mempermudah para pengguna parkir dan 
Tabel 1. Analisis-sintesis perencanaan lansekap Rusunawa Universitas Lampung

\begin{tabular}{|c|c|c|c|}
\hline \multirow{2}{*}{$\begin{array}{c}\text { Unsur } \\
\text { Lansekap }\end{array}$} & \multicolumn{2}{|c|}{ Analisis } & \multirow{2}{*}{ Sintesis } \\
\hline & Potensi & Kendala & \\
\hline Lokasi & $\begin{array}{l}\text { - Letak yang berdekatan } \\
\text { dengan Terminal Rajabasa, } \\
\text { kolam berenang dan } \\
\text { gedung serba guna(GSG). } \\
\text { - Lokasi yang dekat dengan } \\
\text { tempat perkuliahan sehingga } \\
\text { memudahkan mahasiswa } \\
\text { untuk mengaksesnya. } \\
\text { - Memiliki lahan kosong yang } \\
\text { cukup luas sehingga cukup } \\
\text { tersedianya lahan untuk } \\
\text { mahasiswa praktikum dan } \\
\text { membuat fasilitas umum. }\end{array}$ & $\begin{array}{l}\text { - Kurangnya fasilitas dan } \\
\text { kenyamanan. }\end{array}$ & $\begin{array}{l}\text { - Merancang dan menata } \\
\text { keadaan ruang di lingkungan } \\
\text { Rusunawa yang sesuai } \\
\text { dengan kebutuhan } \\
\text { mahasis wa penghuni, } \\
\text { praktikan, serta masyarakat } \\
\text { umum dan dilengkapi } \\
\text { dengan warung kantin yang } \\
\text { dibutuhkan mahasiswa } \\
\text { penghuni, praktikan, dan } \\
\text { masyarakat umum. }\end{array}$ \\
\hline Iklim & $\begin{array}{l}\text { Suhu dan kelembaban yang } \\
\text { tinggi namun diimbangi } \\
\text { dengan angin yang berhembus } \\
\text { cukup kencang dapat } \\
\text { menciptakan suasana yang } \\
\text { nyaman. }\end{array}$ & $\begin{array}{l}\text { - Curah hujan yang tinggi } \\
\text { - Berhembusnya angin } \\
\text { menyebabkan gugurnya } \\
\text { daun-daun dan ranting } \\
\text { sehingga menyebabkan } \\
\text { lingkungan menjadi } \\
\text { kotor. }\end{array}$ & $\begin{array}{l}\text { - Penanaman tanaman pohon } \\
\text { atau tanaman air untuk } \\
\text { meningkatkan infiltrasi agar } \\
\text { tahan terhadap kekeringan. } \\
\text { - Penanaman pohon peneduh } \\
\text { bersifat evergreen untuk } \\
\text { menciptakan iklim mikro } \\
\text { yang sejuk dan bersih. }\end{array}$ \\
\hline Tanah & $\begin{array}{l}\text { - } \text { Tanah Ultisol } \\
\text { - } \text { pH 5,76-7,03 } \\
\text { - KTK rendah } \\
\text { - Tingkat kesuburan tanah } \\
\text { rendah sampai medium. }\end{array}$ & $\begin{array}{l}\text { Tanah sebagian besar } \\
\text { adalah rawa dan liat. }\end{array}$ & $\begin{array}{l}\text { - Penambahan pupuk organik } \\
\text { dan pasir untuk membuat } \\
\text { tekstur tanah lebih porous } \\
\text { dan kandungan hara } \\
\text { meningkat. }\end{array}$ \\
\hline Topografi & $\begin{array}{l}\text { - Kondisi tapak memiliki } \\
\text { kemiringan } 4 \% \\
\text { - Berada di ketinggian } \pm 200 \\
\text { meter di atas permu kaan laut }\end{array}$ & $\begin{array}{l}\text { Terdapat beberapa } \\
\text { daerah yang miring. }\end{array}$ & $\begin{array}{l}\text { - Menanam tanaman yang } \\
\text { memiliki perakaran kuat } \\
\text { agar tidak terjadi erosi. } \\
\text { Contohnya: rumput dan LCC } \\
\text { (Legum cover coops) seperti } \\
\text { kacangan penutup tanah, } \\
\text { Calopogonium caeruleum, } \\
\text { Calopogonium mucunoides. }\end{array}$ \\
\hline Hidrologi & $\begin{array}{l}\text { - Ketersediaan air tanah yang } \\
\text { didapat dengan cara sumur } \\
\text { bor karena sumur bor } \\
\text { ketersediaannya di saat } \\
\text { musim kemarau masih } \\
\text { tersedia dan lebih bersih } \\
\text { dibandingkan dengan air } \\
\text { rawa. } \\
\text { - Terdapat rawa yang dapat } \\
\text { dimanfaatkan sebagai kolam } \\
\text { ikan dan juga untuk } \\
\text { penyiraman tanaman. }\end{array}$ & -- & $\begin{array}{l}\text { Pemanfaatan daerah rawa } \\
\text { sebagai kolam ikan atau } \\
\text { sarana konservasi tanah dan } \\
\text { air. }\end{array}$ \\
\hline
\end{tabular}


Tabel 1. lanjutan

\begin{tabular}{|c|c|c|c|}
\hline Vegetasi & $\begin{array}{l}\text { - Vegetasi didominasi oleh } \\
\text { semak yang tumbuh alami, } \\
\text { seperti alang-alang, dan } \\
\text { tanaman air. } \\
\text { - Terdapat juga pohon, seperti } \\
\text { akasia, melinjo, kembang } \\
\text { kecrutan, kelapa, belimbing, } \\
\text { mangga, mahoni, petai cina, } \\
\text { bambu, durian, dan jengkol. }\end{array}$ & $\begin{array}{l}\text { Lahan sangat gersang } \\
\text { karena sebagian besar } \\
\text { ditutupi oleh alang- } \\
\text { alang. }\end{array}$ & $\begin{array}{l}\text { Pemberantasan alang-alang } \\
\text { dan putri malu dan } \\
\text { digantikan oleh rumput } \\
\text { taman serta penambahan } \\
\text { vegetasi sebagai plasma } \\
\text { nutfah. }\end{array}$ \\
\hline View & $\begin{array}{l}\text { - Pemandangan rawa yang } \\
\text { alami merupakan good view } \\
\text { tetapi belum diolah dengan } \\
\text { baik } \\
\text { - Terminal rajabasa yang } \\
\text { lebih teratur. }\end{array}$ & $\begin{array}{l}\text { Bad view terdapat pada } \\
\text { daerah terminal rajabasa } \\
\text { yang terletak di } \\
\text { belakang Rusunawa. }\end{array}$ & $\begin{array}{l}\text { Melakukan penanaman } \\
\text { tanaman yang berfungsi } \\
\text { sebagai tabir (screen) pada } \\
\text { batas tapak yang memiliki } \\
\text { bad view. Penanaman } \\
\text { dengan tanaman yang tegak } \\
\text { dan ditanam rapat untuk } \\
\text { mengurangi dari kebisingan. } \\
\text { Contohnya: glodokan tiang. }\end{array}$ \\
\hline $\begin{array}{l}\text { Sosial, } \\
\text { ekonomi, } \\
\text { dan } \\
\text { budaya }\end{array}$ & $\begin{array}{l}\text { Rusunawa dihuni oleh civitas } \\
\text { akademika yang terdiri dari } \\
\text { mahasiswa yang memiliki pola } \\
\text { pikir yang terpelajar dan } \\
\text { intelektual, serta memiliki } \\
\text { budaya yang rapi dan teratur. }\end{array}$ & $\begin{array}{l}\text { Mahasiswa berasal dari } \\
\text { latar belakang yang } \\
\text { berbeda dan berasal dari } \\
\text { berbagai daerah yang } \\
\text { berbeda. }\end{array}$ & $\begin{array}{l}\text { Layak untuk menampilkan } \\
\text { rancangan lanskap yang } \\
\text { tepat sehingga dapat } \\
\text { diterima oleh semua } \\
\text { kalangan penggunaan tapak. }\end{array}$ \\
\hline
\end{tabular}

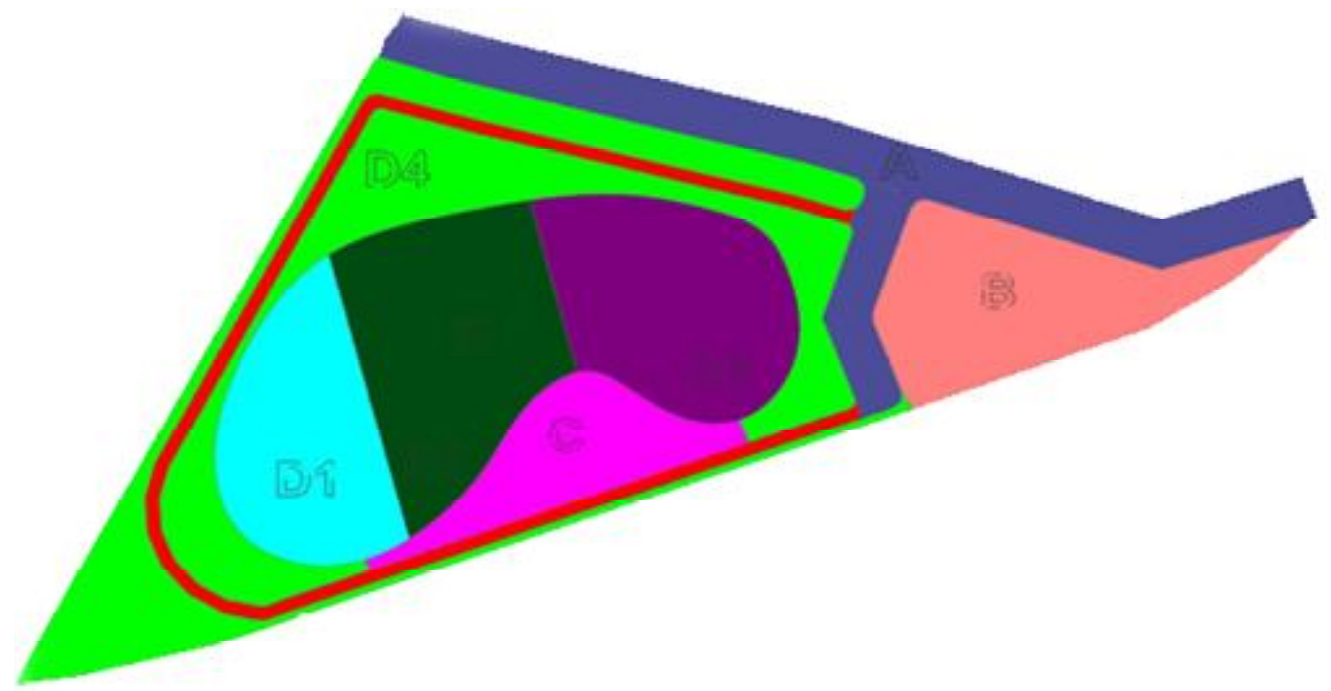

Gambar 5. Konsep zonasi laboratorium praktikum pertanian. A.Zona penerimaan, B. Zona rumah kaca dan tempat buat pengomposan jamur, C. Zona tanaman buah dan sayur, D1. Zona perikanan, D2. Zona penyulingan air, D3. Zona Pemancingan, dan D4. Zona ruang terbuka hijau 

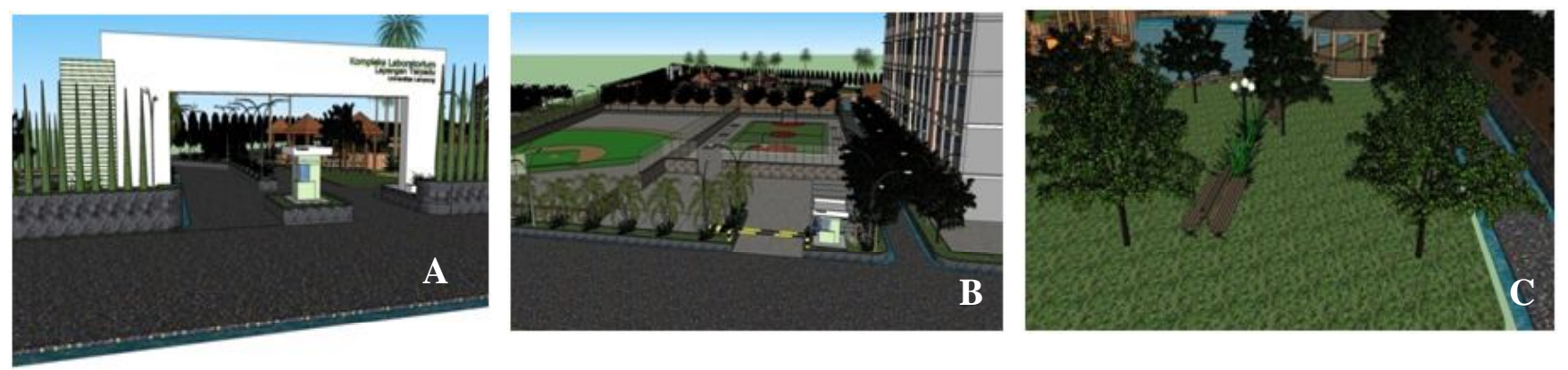

Gambar 6. Blow-up penerimaan (A), Blow-up olahraga (B), dan Blow-up Ruang terbuka hijau (C).
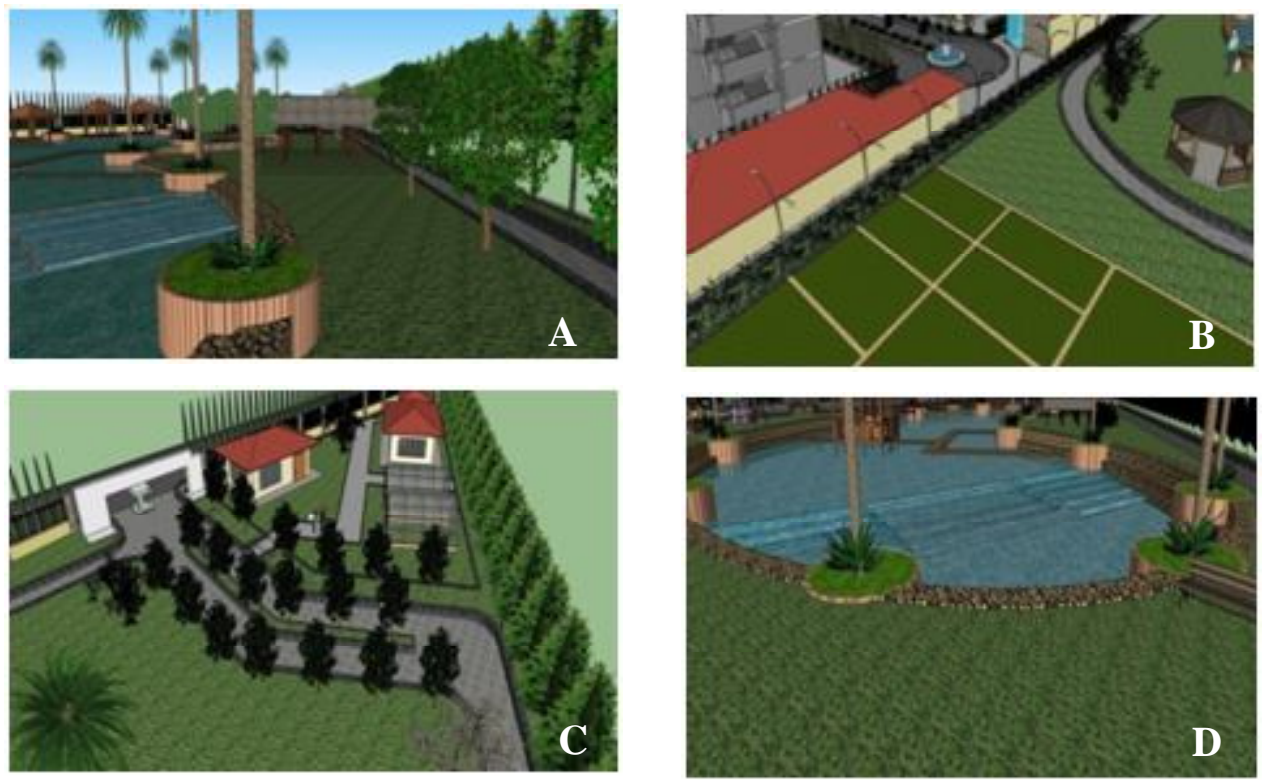

Gambar 7. Blow-up area tanaman sayu dan buah(A), Blow-up area persawahan(B), Blow-up area rumah kaca dan pengomposan jamur (C), dan Blow-up area pemancingan dan perikanan (D).

menghindari saling bersentuhan dengan kendaraan lain. Sudut yang digunakan pada zona parkiran ini adalah $45^{\circ}$ untuk mempermudah para pengguna kendaraan parkir serta memiliki daya tampung kendaraan yang cukup banyak \pm 70 kendaraan roda empat (Gambar 8A).

Zona Rusunawa memiliki luas $\pm 9061 \mathrm{~m}^{2}$, fasilitas yang terdapat pada zona ini adalah bangunan yang dirancang sebagai dua bangunan kembar yang berhadapan dan tempat jemuran pakaian rusunawa, selain itu fasilitas yang terdapat adalah parkir mobil, parkir motor dan rumah genset, kantin mahasiswa, mini market (Gambar 8B).

Jalur sirkulasi yang diterapkan ada dua jalur sirkulasi yaitu jalur sirkulasi untuk kendaraan bermotor dan jalur sirkulasi untuk pejalan kaki. Jalur sirkulasi untuk kendaraan bermotor ditandai dengan garis putus-putus berwarna merah dan jalur untuk pejalan kaki ditandai dengan garis putus-putus berwarna kuning (Gambar 9A).

Fasilitas saluran pembuangan air (drainase) yang terdapat dalam tapak adalah jenis saluran dengan sistem kombinasi drainase semi tertutup dan drainase terbuka. Drainase seluruh saluran mengikuti kontur tapak dan bermuara pada dua bak kontrol berupa kolam Instalasi Pengolahan Air Limbah (IPAL) yang kemudian dialirkan ke kolam pemancingan, jika musim hujan atau pada saat air melimpah sehingga kolam kelebihan air, maka air akan mengalir ke pembuangan yang berada di seberang kolam seperti coberan (Gambar 9B). 

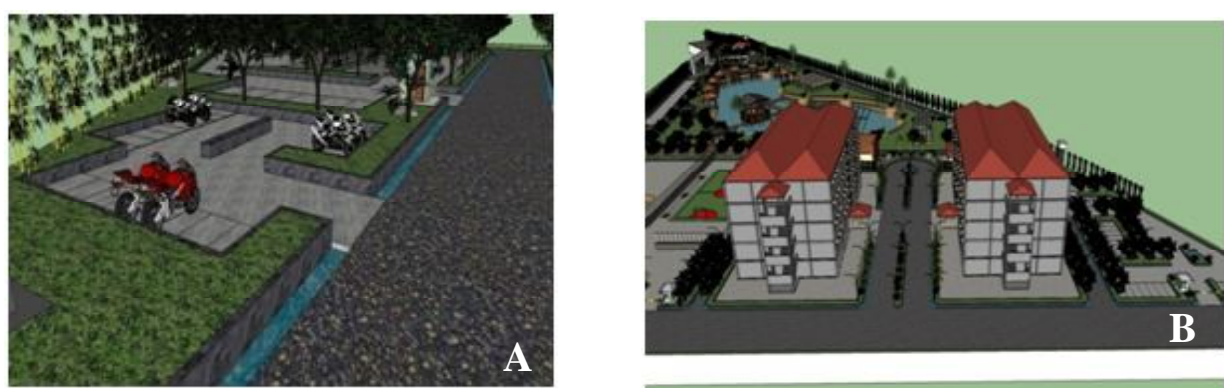

Gambar 6. Blow-up parkiran (A), Blow-up Rusunawa (B).
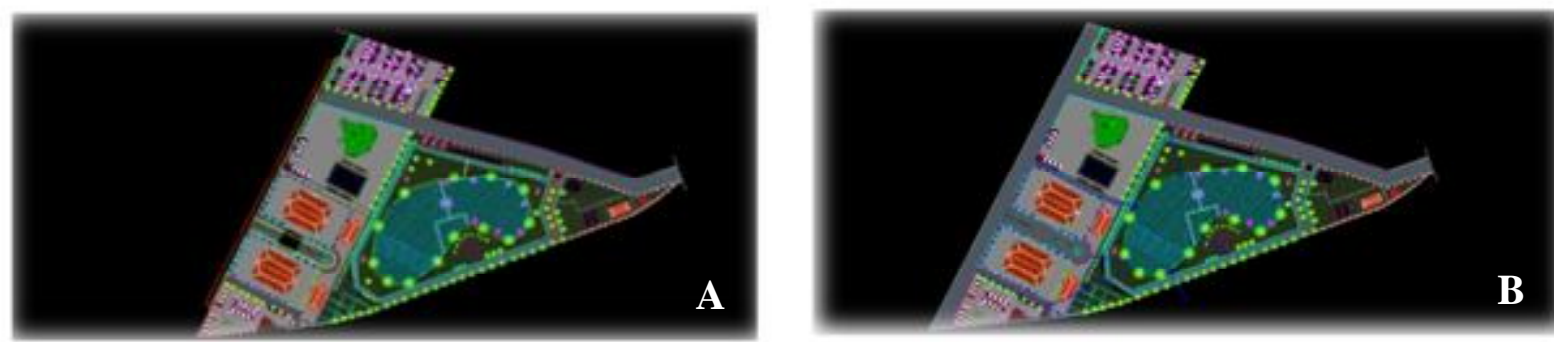

Gambar 6. Konsep sirkulasi (A), Konsep drainase (B).

\section{KESIMPULAN}

Dari hasil pengamatan dan pembahasan pada bab sebelumnya, dapat disimpulkan perancangan lansekap kawasan Rusunawa Universitas Lampung diharapkan menjadi laboratorium praktikum bagi mahasiswa serta dosen Fakultas Pertanian sehingga dapat meningkatkan mutu pendidikan dan dapat menghasilkan kelulusan yang baik. Dari hasil analisis sintetis yang telah dibuat dapat dilihat gambaran bahwa kawasan Rusunawa Universitas Lampung berpotensi menjadi laboraturium praktikan yang terbagi menjadi tujuh zona ruang, yaitu zona penerimaan Adan zona penerimaan $\mathrm{B}$, zona olah raga, zona rusunawa, zona ruang terbuka hijau, zona praktikum dan zona parkiran umum.

\section{DAFTAR PUSTAKA}

Arifin, S.H., dan N, Arifin. 2000. Pemeliharaan Taman. Penebar Swadaya. Jakarta. $123 \mathrm{hlm}$.

Gold, S. M. 1987 Recreation Planning and Design. Mc Graw-Hill Book Company. Toronto. 134 hlm.
Hakim, R 1987. Unsur Perancanagn Lansekap Dalam Arsitektur Lansekap. Bina Aksara. Jakarta. 176 hlm.

Hakim, R. dan H. Utomo. 2008. Komponen Perancangan Arsitektur Lansekap: Prinsip Unsur dan Aplikasi Desain. Bumi Aksara. Jakarta. 242 hlm.

Irwan, Z.D. 2005. Tantangan Lingkungan \& Lansekap Hutan Kota. Bumi Aksara. Jakarta. $179 \mathrm{hlm}$.

Laurie, M. 1975. An Introduction to Landscape Architecture. American Plublisher. Dalam Komponen Perancangan Arsitektur Lansekap. Rustam Hakim dan Hardi Utomo. 2008. Bumi Aksara. Jakarta. $242 \mathrm{hlm}$

Simond, J.O. 1983. Landscape Architecture. McGraw-Hill. New York. 331p.

Suharto. 1994. Dasar-dasar Pertanaman Menciptakan Keindahan dan Kerindangan. Media Wiyata. Jakarta. $196 \mathrm{hlm}$.

Sinta, M. dan Murhananto. 2004. Mendesain, Membuat, dan Merawat Taman Rumah. Agromedia Pustaka. Tangerang $113 \mathrm{hlm}$. 